\title{
Branded Web-Series And Its Impact On The Indian Gen- Y And Gen-Z Consumers
}

\author{
Gresshma Bharathan
}

\author{
Marketing,Pandit Deendayal Energy University \\ DOI: 10.29322/IJSRP.11.08.2021.p11679 \\ http://dx.doi.org/10.29322/IJSRP.11.08.2021.p11679
}

\begin{abstract}
With rapid digitalization currently taking place in India, young Indian adults have been heavily relying on digital media for entertainment content that discusses unconventional topics and resonates with their mindset, which traditional Indian TV programs often fail to do. This change in viewing habit coincides with marketers looking for new marketing communication tools to cope with the changing advertising landscape. This change can be attributed to the ailing effectiveness of traditional advertisements due to clutter, technology-enabled ad-zapping which is accompanied by declining attention paid to advertisements and increasing defensiveness of consumers towards ad-persuasions. Branded web-series are produced or co-produced by the brand themselves and hence, the narrative is centred around the brand. This enables marketers to cope with the challenges faced by traditional advertisements for their brands by associating the brand with appealing content. Such branded web-series are becoming a part of brands trying to adopt marketing through engagement rather than interruption and is being explored as an alternative by marketers since it conveys the brand message while keeping the audience engaged and entertained. This research aims to 1) Understand the evolution of branded web-series from simple product placements 2) Examine its edge over traditional advertisements and in-film placements 3) Evaluate its influence on GEN-Y and GEN-Z Indian consumers on the basis of factors like brand-awareness, brand-recall, brand-attitude and preference. The overall goal of this research is to provide more insight on this growing trend to marketers whose target market predominantly consist of young adults.
\end{abstract}

The research involved analyses of secondary and primary data. The primary data was collected using survey methodology. A questionnaire was circulated amongst 112 viewers of Indian web-series from various cities of India, belonging to the age-group of 17-40. The questionnaire consisted of two sections, the first section aimed to evaluate the viewing habits among respondents and the second section aimed to evaluate the perception and impact of the brands placed in Indian web-series on the basis of their experiences with some of the most popular web-series.

The results indicate that branded web-series are more successful than traditional advertisements at capturing attention and building a positive brand image, particularly amongst younger consumers. Its effectiveness is highest when the brand is embedded into a relatable narrative organically. It creates brand awareness and improves brand recall while developing positive brand attitude and increasing brand loyalty. However it is observed that purchase intentions are not directly influenced by these branded web-series . Further research can be carried out to understand how factors such as popularity and identification with the actors can influence the effectiveness of branded web-series.

Index Terms- Branded web-series, Product placements, Brand recall, Brand attitude,Purchase intention Indian consumers.

\section{INTRODUCTION}

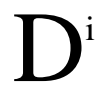
igital India And Advent Of Web-Series

India is experiencing a surge in internet usage every year, currently, there are over 525 million internet users in India and about $67 \%$ of them are under 35 years of age(Statista,2019).This growth can be attributed to the availability of cheap data plans and several digitization projects undertaken by the Indian government. Increasing accessibility to the internet has caused a boom in online video streaming amongst the youth and the growth of several OTT (over-the-top platforms) in the Indian market. Popular OTT platforms like Hotstar, Amazon Prime and Netflix have 300 million,13 million and 11 million Indian subscribers majorly belonging to 18-34 years of age respectively(BusinessToday,2019).The Indian entertainment industry is facing a structural shift from TV viewing to online entertainment. This 'shift in eyeballs' can be understood by preference of the millennials or Gen-Y and the Gen-Z towards onthe-go viewing to suit their busy lives rather than scheduled viewing. The majority of younger Indian viewers are commute streamers who watch online content on their way to college, work and back home .By 2022 it is expected that India would be amongst the top 10 video streaming markets (Livemint, 2019).Another key driving factor is the lack of content on TV that caters well to the younger population. Indian TV programmes still majorly revolve around family drama and is often overdramatized .They are rarely based on contemporary topics and hence the Indian Gen-Y Gen-Z population heavily reply on foreign shows for relatable and fresh content. The American sitcom 'FRIENDS' that discuss the every-day lives of young adults have a large Indian audience with over 2.08 million impressions (Livemint,2016).Online content creators did recognize this gap in the Indian entertainment industry and started creating content online based on several unconventional and taboo topics without the tight constraints of censorship the TV programmes are subjected to. This led to the advent of Indian web-series. Webseries is similar to a TV series but it is released on an online platform in a series of episodes called 'webisodes'. The first Indian web-series 'Permanent Roommates' released by TVF on their 
YouTube channel in 2014 based on a live-in relationship, tasted huge success with over a million views per episode(Hindustantimes,2016). This success was followed by the success of several web-series released thereafter discussing a plethora of subjects like friendships, dating lives, same-sex relationships, women-empowerment, social injustice and so on.

\section{Brands And Web-Series}

Marketers whose target markets predominantly consist of young adults have been finding it increasingly difficult to reach them through TV advertising. They resorted to online advertising and pre-video and in-video ads, however these can be skipped and hence failed to create lasting impressions. These ads are also viewed to be interruptive and $53 \%$ of the internet users in India use ad blocking tools. (Datareportal, 2019).Advertising in general has been facing challenges and is experiencing a decline in its effectiveness. According to a survey conducted by the Association of National Advertisers TV Ad forum, about $78 \%$ of advertisers are losing confidence on advertising(Adage, 2008).This decreasing effectiveness can be understood by challenges posed by ad clutter, attention becoming scarce and deterioration in the quality of attention paid. Majority of the TV viewers divert their attention when an ad comes on by switching channels, by performing other activities or using other devices simultaneously like their mobiles or laptops (two-screen concept).People are also becoming increasingly sceptical of ads after being bombarded by persuasive messages and are often annoyed by them. Technology now enables the viewers to skip ads, further making it difficult for advertisers to reach them. The growth of subscription based platforms like Netflix and Spotify premium that sell ad-free experiences shows the willingness of people to spend extra money to have an uninterrupted experience. Marketers have experimented with in-film product placements in Indian movies as an alternative to traditional advertising and have continued to do so. The boxoffice hit movie Kuch Kuch Hota Hai released in 1998 had 144 placements and the recent hit film Gully Boy had over 20 brands placed(Fincancialexpress,2019)The effectiveness however depends on the execution of the placement, it often suffers from clutter when too many brands are placed, going unnoticed when placed too subtly placed or making the audience defensive when blatantly placed. The rise of web-series was seen as an opportunity for marketers to reach their targeted and ready-made audience rather than a wide audience as in the case of films. Initially, webseries carried placements similar to that in films where it was used as a prop or became a small part of a scene. Its success motivated brands to further invest, Nerolac spent Rupees 5 million to buy $30 \%$ screen space in the series Aam Aadmi Family (Socialsamosa, 2017). These placements have now evolved into full-fledged branded web-series which is produced or co-produced by the brand themselves. Brands are closely incorporated into the narrative and they play a key role in the development of the narrative. The brand is not treated as a mere prop or as an "extra". The brand message is communicated gradually as a part of the story and hence is not only non-interruptive, but also adds to the entertainment factor. This helps the brand break through the clutter due to exclusivity and create a lasting impact through its relevance and presence throughout the series. Brands are creating content that can propagate their brand philosophy and their stand on contemporary issues that resonate with the younger consumers and hence build an emotional connection with them. The content on these web-series is different from the more vanilla content on traditional TV and is more risque which is refreshing. The main goal of branded web-series is to create brand awareness, build positive brand associations, and seem relevant to the consumer and thereby improving brand attitude and building brand loyalty. Apart from that, they have been found to positively impact sales. The online jewellery store Velvetcase experienced a $238 \%$ increase in their website traffic after the release of the webseries "Little Things" that they co-created (Thehindubusinessline, 2017).The success of these web-series can be explained by the fact that the brand message is presented to a the audience in a creative and less persuasive manner when they are in an attentive state and emotionally invested in the storyline and the characters. This psychological state enables them to process the information presented better and their sentiments generated can benefit the associated brand. Vani Gupta, ex marketing director, Pepsico India believes that branded web-series can seem more credible than ads and occupy a larger place in the consumer's mind (Thehindubusinessline, 2017). Branded web-series portray the brand or product as an integral part of the every-day lives of the character and this adds verisimilitude. Marketers are attempting to maximize the effectiveness of branded content by trying to understand the right combination of factors which impact the effectiveness of product placements in various entertainment vehicles. Some of these factors include the level of integration of the brand into the plot, the frequency and length of brand exposure, mode of presenting the brand and prominence of brand placement. Comparing branded web-series to simple product placements, the former can be considered more ethical since the viewers are aware that they are being presented with branded content and hence expect the brand to be a part unlike product placements that do not carry disclosure. This transparency helps to build trust amongst consumers and hence is beneficial in the long run. Branded webseries offer a win-win situation for the consumers as well as the marketeers.

\section{OTT Growth In India During COVID-19}

Since the lockdown was announced initially during March 2020, OTT platform in India experienced a major spike as a result of the increased online content consumption.OTT platforms experienced a boom within the first few months of the lockdown itself.During this period, the viewership on these platforms grew immensely due to people staying indoors,working from home and having more free time.This caused people to seek out more diverse entertainment content content online to keep themselves entertained and get through the stressful times.There was an increased viewership of both regional and foriegn content on these platforms. The increased free time was also complimented by a major factor that theatres were shut down too. With theatres being shut down major new movie releases took place on these OTT further garnering viewership, for example, the Bollywood movie "Dil Bechara" premiered on Disney+Hotstar and saw the biggest opening ever. The popularity of these shows and increasing viewership also provided the impetus to the OTT platforms to come up with a lot of original content catering to diverse audiences thus furthering the reach. An interesting phenomenon was how the popularity of these OTT platforms spread from the metropolitans to the lower-tier cities during this period and growth in viewership 
among small-town audiences. According to the India brand equity foundation, OTT platform experienced a spike of $31 \%$ in their paid subscription just between April and July of 2020 taking the total OTT subscriptions in the country to 29 million(Livemint,2020)According to BCG estimates there has been a $14.5 \%$ increase in the average daily time spent on these platforms within the last two years alone(businessstandard,2020)This growth has been incentivising the platforms to improve the content to grab more eyeballs and retain the existing audience even after the situation returns to normalcy particularly the small-town audiences. The current content creation philosophy of most of these platforms have been to create eclectic content so that there is something for everyone. By 2023 it is expected that the OTT market in India would be evaluated at 5 billion US dollars and would be one of the top 10 global OTT markets(mordorintelligence,2021). Even in March 2021 when there initially was an ease in the restrictions, a $20 \%$ viewership growth was expected in 2021(livemeint,2021).

\section{Research Problem}

The background provided in the preceding section sheds light on how Indian young adults have been heavily relying on digital media for entertainment content and how this change in viewing habit coincides with marketers looking for new marketing communication tools to cope with the

changing advertising landscape.One such alternative that is being explored is branded web-series.Branded web-series are produced or co-produced by the brand themselves and hence, the narrative is centered around the brand. This enables marketers to cope with the challenges faced by traditional advertisements for their brands by associating the brand with appealing content.This paper aims to understand factors that affect the effectiveness of these branded web-series and measuring its impact against variables such as brand recognition,brand awareness,brand recall,brand memory,brand attitude,brand loyalty and purchase intentions. This study would thus provide better insights about this growing trend to marketers, whose target market predominantly consists of young Indian adult

Consumers.

\section{Research Objectives}

1) Examine its edge over traditional advertisements and in-film placements 2) Evaluate its influence on GEN-Y and GEN-Z Indian consumers on the basis of factors like brand-awareness, brand-recognition and recall, brand-attitude, purchase intention and brand-loyalty.

3) Evaluate its effectiveness and efficiency as a promotional tool in the digital age.

\section{LITERATURE REVIEW}

\section{Product Placements Abroad And In India}

(Balasubramanian et.al, 2006)The impact of product placements depends on execution factors such as modality, fit to the narrative, prominence, character using the product and individual factors like scepticism, familiarity and identification with the brand. Visual and verbal combinations of placement had the highest impact, followed by verbal only and then visual only. Character's attitude towards the brand and the consumer's perception of how the brand can impact his self-identity and social image affects effectiveness. When the brand establishes a connection with the consumers through the content they tend to ignore the commercial intent and help in validating their purchasing behaviours. People who held a more positive disposition about traditional ads were also more positive towards product placements and it is observed that men were more accepting of placements of ethically charged products than women.

(Gupta and lord, 1998) While watching a movie people are willing to process information presented to them for a stimulating experience. Therefore when brands are placed in entertainment vehicles, they enjoy the advantage of higher information processing thus increasing its impact.

(Russel,2002)

Discusses the effectiveness of product placements based on mode of placement and its prominence. It is found that audio placements that are key to the plot was more effective than subtle visual placements due to higher attention paid to and processing of the audio messages. The congruency between a brand being represented and its significance to the plot also highly impacts the positive effects it has on the viewer's mind.

(Gupta and Gould,2012) Consumer's perception of ethics and acceptability of product placement in movies. Product placements have taken various forms from and have been used as a mode of promotion within various forms of entertainment such as songs, games, movies, books etc. In film and in series placements particularly have been explored and leveraged due to their high popularity. For example, due to the placement of Reese's Pieces in the movie ET, the brand experienced a sales growth of $65 \%$ within a month. But it is crucial to look into the ethics and acceptability of these placements to continue using this as a means of promotions and impact consumer attitudes and purchase intentions positively. The effectiveness of placement varies with the product category, for example, It is seen that ethically-charged products such as alcohol, cigarette and other products may be less acceptable and might also be seen as repulsive because it was attempted to pursue the audience without direct labelling as advertisement and may also promote negative behaviour in the audience, thus such placements must be refrained from. Also correlations were found between the effectiveness of the integration and individual differences and gender differences. The audience who more often watched films and tv shows were more accepting of placements than those who didn't. Women were also seen to be more critical about the of ethically charged products than men. Thus there are several nuances underlying the impact different placements have on diverse audiences.

(Karrh et al ,2003)Product placements have been prevalent since the end of World War 2 and its prominence has been growing ever since.It has evolved beyond a barter system enabling lowering of production cost in turn for promotions to full-fledged sponsorships and paid collaborations. Within the industry, Practitioners hold the belief that various factors influence the outcome of these placements, but it carries immense potential and can complement traditional advertising. Practitioners believe that already established brands would benefit more from placements than the newer ones. Increased sales and media coverage is considered to be key measures of the success of the placements. 
(Diwan,2017)Indian films adapted product placements soon after their success in the west and experimented with various formats of it. entertainment vehicles, they enjoy the advantage of higher information processing thus increasing its impact.

(Russel,2002)

Discusses the effectiveness of product placements based on mode of placement and its prominence. It is found that audio placements that are key to the plot was more effective than subtle visual placements due to higher attention paid to and processing of the audio messages. The congruency between a brand being represented and its significance to the plot also highly impacts the positive effects it has on the viewer's mind.

(Gupta and Gould,2012) Consumer's perception of ethics and acceptability of product placement in movies. Product placements have taken various forms from and have been used as a mode of promotion within various forms of entertainment such as songs, games, movies, books etc. In film and in series placements particularly have been explored and leveraged due to their high popularity. For example, due to the placement of Reese's Pieces in the movie ET, the brand experienced a sales growth of $65 \%$ within a month. But it is crucial to look into the ethics and acceptability of these placements to continue using this as a means of promotions and impact consumer attitudes and purchase intentions positively. The effectiveness of placement varies with the product category, for example, It is seen that ethically-charged products such as alcohol, cigarette and other products may be less acceptable and might also be seen as repulsive because it was attempted to pursue the audience without direct labelling as advertisement and may also promote negative behaviour in the audience, thus such placements must be refrained from. Also correlations were found between the effectiveness of the integration and individual differences and gender differences. The audience who more often watched films and tv shows were more accepting of placements than those who didn't. Women were also seen to be more critical about the of ethically charged products than men. Thus there are several nuances underlying the impact different placements have on diverse audiences.

(Karrh et al 2003)Product placements have been prevalent since the end of World War 2 and its prominence has been growing ever since.It has evolved beyond a barter system enabling lowering of production cost in turn for promotions to full-fledged sponsorships and paid collaborations. Within the industry, Practitioners hold the belief that various factors influence the outcome of these placements, but it carries immense potential and can complement traditional advertising. Practitioners believe that already established brands would benefit more from placements than the newer ones. Increased sales and media coverage is considered to be key measures of the success of the placements.

(Diwan,2017)Indian films adapted product placements soon after their success in the west and experimented with various formats of it.

The 4 main types included the classic placement wherein the particular product is part of the scene as a prop, corporate placement wherein the focus is on the brand than a particular product, evocative placement wherein the brand name or logo is not directly visible but its specific packaging enables recognition and finally stealth placement which is more subtle and credible due to appropriate integration into the plot naturally and this is seen to be most effective.
(Kakkar and Nayak,2019) -sheds light on the effectiveness of traditional product placements in Indian web series that have been attracting attention from several brands with the growth of online entertainment content demand in the country. It is observed that even placements within web series can be more impactful, viewed to be more credible by the audience and less expensive than traditional advertising. Web series help reach a specific targeted audience and thus to leverage the effectiveness of brand integration into web series it is key to choose the right series to collaborate with that your target audience would resonate with.

Development Of Branded Entertainment

(Russell, 2007) She coined the word 'Advertainment' to describe the increasing intermingling of advertising and entertainment. It includes the incorporation of brand communications into an entertainment vehicle. Advertainment has been growing rapidly as traditional advertising is facing a decline in its effectiveness due to factors such as decline in the attention span of people, technology enabled ad-skipping, ad clutter and their high costs of production. The intermingling of entertainment and advertising that started off as simple product placements in the early $20^{\text {th }}$ century has now evolved into full-fledged branded entertainment which refers to the highest level of product integration. Brands take up the role of the producer or co-producer and have a say on the centrality of the brand in the storyline. The effect of advertainment has been classified using the hierarchy of effects theory which categorises the impact on the audience into a cognitive stage that includes brand exposure and brand awareness, an effective stage that includes the development of positive brand attitudes and finally a behavioural stage which focuses on actions taken like purchase. Advertainment is found to be most effective when the brand message is subtle and its placement blends into the content naturally. Blatant presentation and overdoing it causes the viewers to become aware of the persuasive intent making them defensive and causing a negative impact.

(Hudson and Hudson, 2006)Branded entertainment is a more sophisticated and elevated form of product placement. The development of branded entertainment has roots in the barter arrangement in which the marketers provided props and helped promote the film in return of placements in the film. Unlike product placements, branded entertainment ensures exclusivity hence increasing its impact. While placements that are prominent and do not fit to the entertainment content increases brand recognition and recall, it negatively affects brand attitudes. Organic and subtle integrations generated positive brand attitudes. The effect of branded entertainment also depends on individual and cross-cultural differences. The lack of strict regulations has led to the wide proliferation of branded entertainment in India, China, New Zealand and Australia.

(Choi, 2015) Growing technology has reduced the physical difference between brands. Consumers now seek emotional satisfaction rather than just physical satisfaction from brand usage. Branded entertainment enables brands to build and maintain a strong brand identity. According to the advertising effect brand, likeability is directly related to advertising likeability, if the consumers like the content they will like the brand. Brands have become a means of self-expression and creating content that connects to the consumers increases brand likeability and make them want to be associated with the brand. 
(Fulgoni and Lipsman, 2017) Commoditization of the inventory by programmatic advertising is facing backlash among digital advertisers which has led to the growth of Branded entertainment. While traditional advertising struggles to capture attention which has become a scarce resource, branded content enables better reception of brand messages since it reaches them at an engaged state of mind. The effect of branded content measured using cognitive theory which says that the deeper the stimuli are processed, the greater its impact on memory. Branded content contains audio-visual placement of brands which enables serial and parallel processing which increases memory and verbal mentions act as memory cues.

(Nagar, 2016)Examines the differing degree of influence of brand placements when placed within regional entertainment compared to to international entertainment. Indian film placements are seen to generate more positive impact on audience than placements in foreign entertainment. Major factors that contribute to this such as cultural relatability and strong influence of familiar and celebrated movie stars. The fit of the placement in the storyline is a key determinant of how well the placement is perceived and the higher the fit, the more positive is the reception and attitude towards the brand placed. However, in the case of misfit, foreign movies tend to suffer more than regional movies and one logical explanation is the varying lengths of the film and the longer format of Indian films compared to Hollywood films causes the audience to overlook the misfit. Thus multinationals should consider Indian films for placements if they are looking to target the Indian audience rather than Hollywood movies even if they're popular among the Indian audience in order to maximize impact.

\section{Challenges To Traditional Advertising}

(Friestad and Wright, 1994)They provide the persuasion knowledge model to understand how people respond to persuasive attempts in ads. People gain knowledge about persuasive attempts over time with experience and use this to defend themselves and tackle future persuasions. Persuasion knowledge makes people more sceptical and defensive towards ads which causes them to ignore ads or be cynical or counter- argumentative and thus it negatively impacts purchase intentions. Thus, when the brand message is presented in a more natural and fitting manner, it decreases consumer scepticism and defensiveness thus resulting in maximum impact.

(Thales s Teixeira,2014)Advertisers have to look for economic ways to grab the attention of the audience for the message to be processed and in turn, persuade and influence consumers. More

the attention the consumer pays, the more they get persuaded. This attention can either be paid for or earned. Earning attention ensures more positive results as the consumers themselves develop interest and engage with the advertising messages. As attention becomes scarce, the quality of paid form of attention keeps declining but its expense keeps rising. The attention paid to traditional ads are seen to be drastically declining when experiments were carried out using eye-tracking and other technology. It is seen that currently only about $20 \%$ attention is paid to ads viewed in comparison to $97 \%$ in the 90 s. This decline in attention can be attributed to multiple factors like ad zapping, clutter, multitasking, distrust or shorter attention span in general. Thus it becomes important to explore new ways to earn attention by creating compelling content or formats. With the internet boom, advertisements became more entertaining than informative because consumers could seek information online thus paid less attention to informative ads that did not interest them. Thus the mixing of entertainment and advertising began to rise and thus led to various forms of non-traditional advertising such as placements and self-entertainment content creation. These practices are referred to as lean advertising strategies.

\section{Research Gap}

Most of the available literature currently discusses branded entertainment as a growing trend in the western world and its potential in the Indian context has not been completely explored yet. In the Indian context, in-film placements and its effectiveness has been studied extensively and have benefited marketers. Similarly understanding the effectiveness of branded web-series with respect to the cultural shift occurring in India due to rapid digitalization, globalization and the pandemic would enable marketers to efficiently allocate their resources to promote their product to their target markets.

\section{Research Methodology}

For this research, survey methodology using convenience sampling has been employed to obtain primary data apart from a comprehensive study of secondary data. An online questionnaire was designed and circulated via google forms for the collection of primary data.

Participants

112 respondents both male and female belonging to the age group of 17-40(GEN-Y and GEN-Z) participated in the survey from various cities of India primarily tier 1 and tier 2 cities

-

Ahmedabad,Anand,Bhavnagar,Bhopal,Calicut,Chennai,Gandhin agar,IndoreJamnaga r,Kochi,Na vsari,Neemuch,Pondicherry,Pune,Rajkot,Salem,Surat,Trivandru $\mathrm{m}$,Trichy,Udaipur and Vadodara.It was requested that only those who watch Indian web-series participate in the survey to ensure valid responses. The participants were contacted through platforms such as Whatsapp,Facebook and Instagram.

\section{Research Design}

The survey form consisted of three sections close-ended questions,the first section included 2 demographic questions regarding age and gender. The second section was designed to collect information on the patterns and sources of entertainment viewing. The third section was designed to obtain information on the impact of branded web-series on the respondents based on their experiences with some of the most popular Indian web-series using variables such as brand awareness, brand recognition \& recall, brand attitude, purchase intentions and brand loyalty.

\section{Variables Measured}

1.Brand awareness: "It is the probability that consumers are familiar about the life and availability of the product. It is the degree to which consumers precisely associate the brand with the specific product.'(managementstudyguide.com) 
2.Brand recognition: "It is the ability of the consumer to recognize prior knowledge of brand when they are asked questions about that brand or when they are shown that specific brand" (managementstudyguide.com)

3.Brand recall : "It is the potential of the customer to recover a brand from his memory when given the product class/category, needs satisfied by that category or buying scenario as a signal."(managementstudyguide.com)

4.Brand attitude : "It tells what people think about a product or service, whether the product answers a consumer need, and just how much the product is wanted by the consumer.'(allbusiness.com)

5.Brand loyalty: "Brand loyalty is a pattern of consumer behavior through which consumers tend to get committed to a specific brand or product and make repeat purchases over time over competitors." (marketingtutor.com) 6.Purchase intention : " It is the degree of willingness and inclination of consumers to buy a product or service within a certain period of time."

\section{DATA ANALYSIS AND FINDINGS}

\section{SECTION 1-DEMOGRAPHICS}

\section{Gender}

112 responses
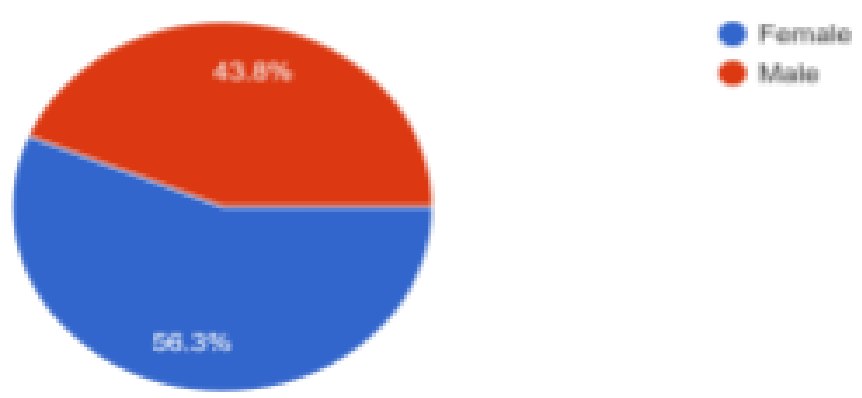

Age

112 responses

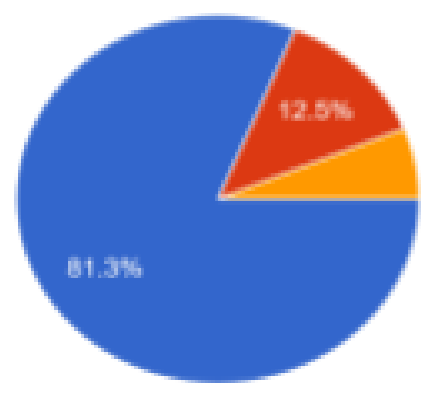

$56.3 \%$ out of the 112 respondents were women and the remaining $43.7 \%$ were men. $83.1 \%$ of them belonged to the age group of 17 $23,12.5 \%$ belonged to the age-group of $24-30$ and the remaining $6.2 \%$ were aged $31-40$. 


\section{Which Indian city do you belong to?}

112 responses

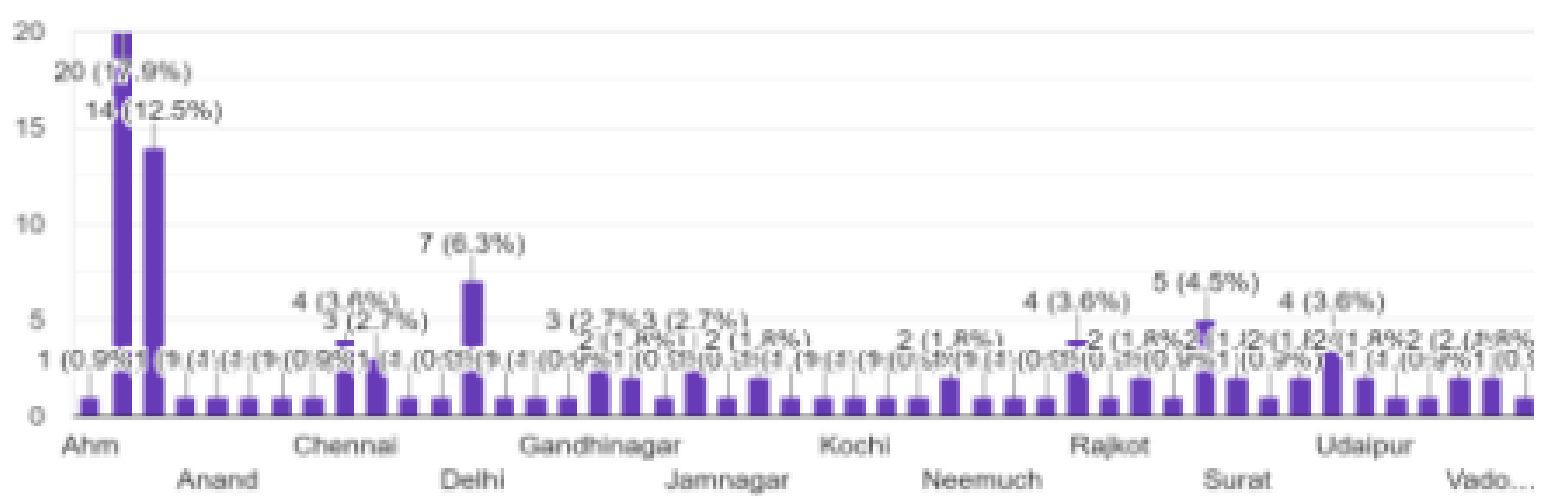

The respondents belonged to various cities of India including

Ahmedabad,Anand,Bhavnagar,Bhopal,Calicut,Chennai,Gandhinagar,IndoreJamnagar, Kochi,Nav

sari,Neemuch,Pondicherry,Pune,Rajkot,Salem,Surat,Trivandrum,Trichy,Udaipur and Vadodara.The highest number of respsondents belonged to Ahmedabad(30.4\%) and Delhi(6.3\%)

\section{SECTION 2-VIEWING HABITS}

What do you prefer to watch in your free time?

112 responses
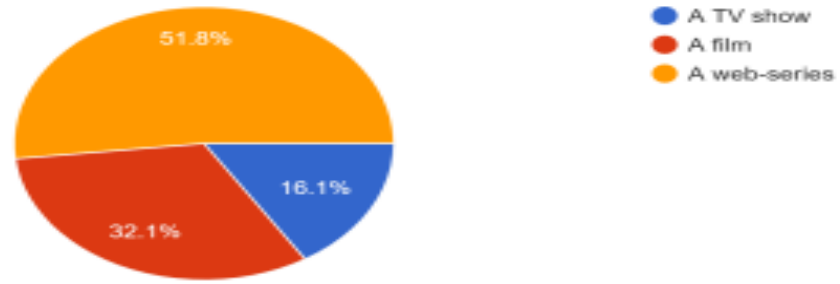

$51.5 \%$ of the respondents thus the majority preferred to watch a web-series compared to a film which was preferred by $32.1 \%$ and a TV show which was preferred by $16.1 \%$ of the respondents.

\section{On an average,which of the following do you spend more time watching?}

\section{2 responses}
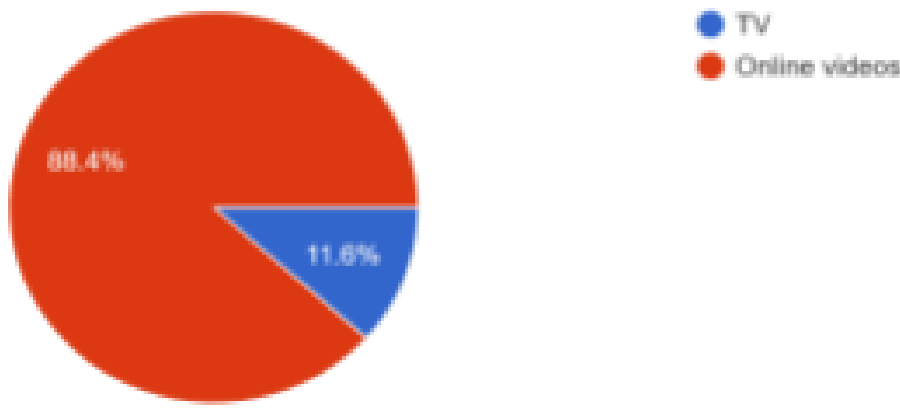

$88.4 \%$ of the respondents preferred watching online videos over TV, while $11.6 \%$ preferred TV. Thus online content was a more popular choice among the respondents. 
Which are some of the platforms that you use to watch videos online?

112 responses

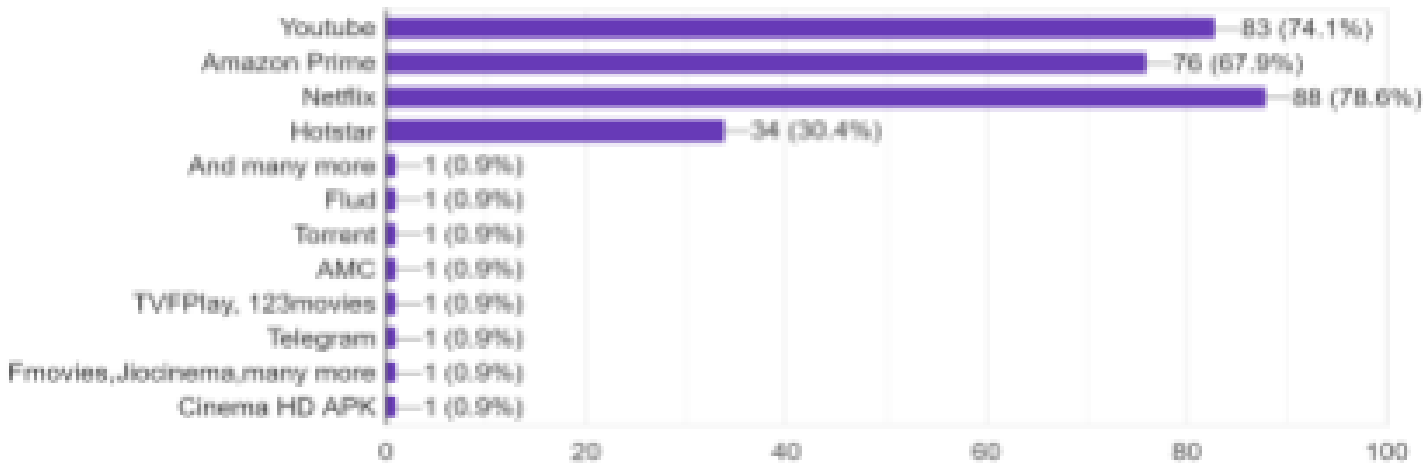

Netflix, YouTube, Amazon Prime and Hotstar are the most used platforms for online content viewing with 78.6\%,74.1\%,67.9\% and $30.4 \%$ of respondents using them respectively. The respondents could select more than one platform, hence the data is overlapping.

\section{If you prefer watching a web-series over a TV programme or film,what are the TWO main reasons for this preference?}

112 responses

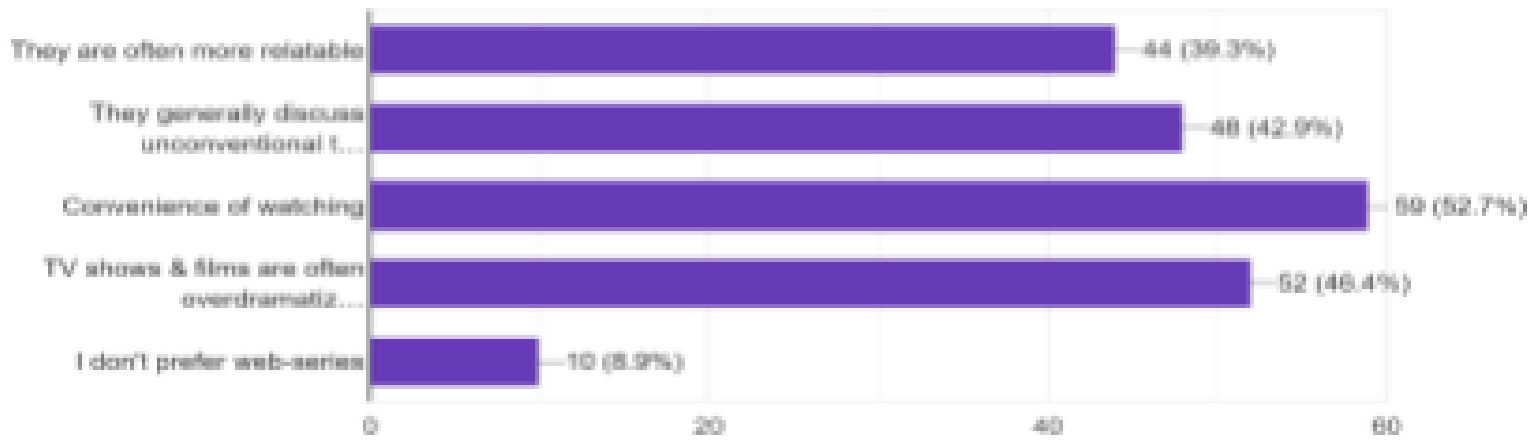

Out of the 102 respondents who preferred to watch web-series over films and TV, 52.7\% held preference due to convenience of watching, $46.4 \%$ due to the overdramatization and repetitiveness in TV programmes and films, $42.9 \%$ due to its discussion of unconventional topics and $39.3 \%$ preferred web-series because they find them more relatable. 


\section{While watching TV, how often do you switch channels when an ad comes on? \\ 112 responses}
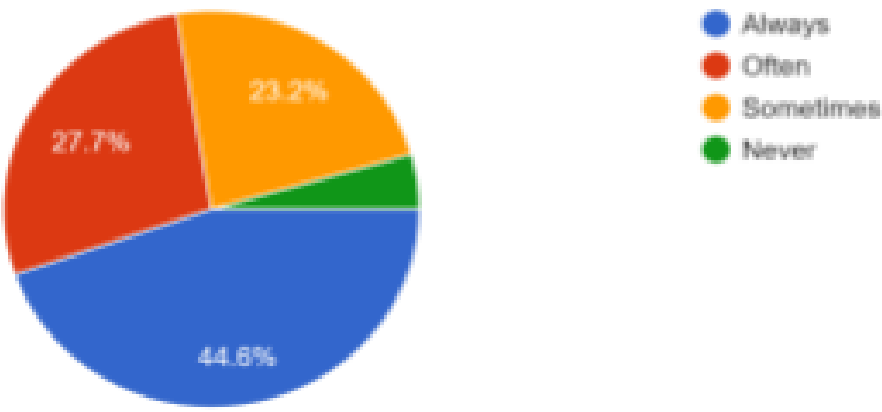

Close to half the respondents i.e $44.6 \%$ of them said they always switch channels to avoid ads and $27.7 \%$ did so often and $23.2 \%$ switched channel sometimes.Only a mere $4.5 \%$ of respondents never switched channels to avoid ads. Thus it is seen that over $95 \%$ of respondents avoid ads by switching channels at some point.

\section{How often do you skip pre-video ads or ads in between the video while streaming videos online?}

112 responses

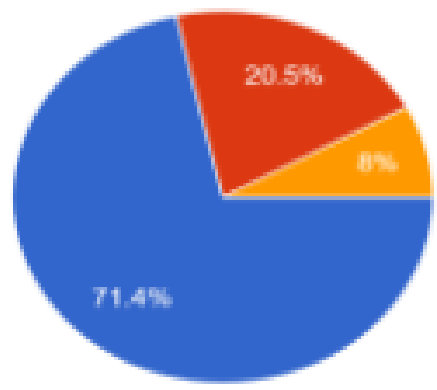

Never

In case of online video ads, $71.4 \%$ respondents skip ads always, $20.5 \%$ skip them often, and $8 \%$ skip them sometimes while none of them always watch an online ad. This suggests that most audiences do not prefer to watch ads and skip them most of them times. In case of online ads, technology enabled ad-zapping results in most ads being skipped. 


\section{Do you think one of the biggest perks of subscription based platforms like Netflix is that they are ad free?}

112 responses
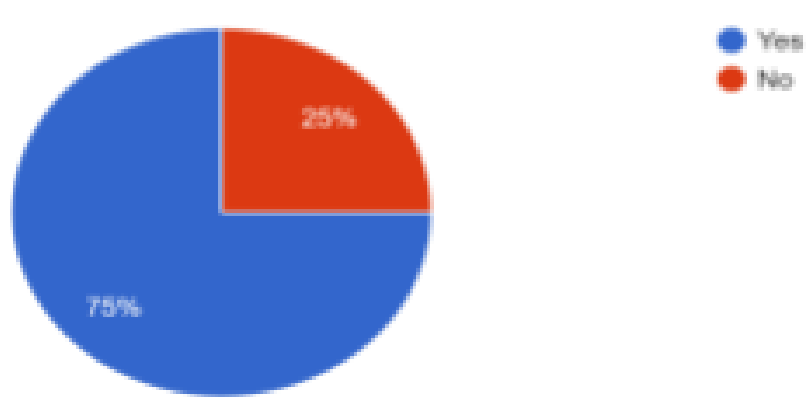

$75 \%$ of respondents feel that ad-free experiences drive them towards subscription platforms like Netflix and Amazon prime. Hence "AD-FREE" is now becoming one of the USPs of such platforms.

SECTION 3-IMPACT ON CONSUMERS

Do you notice brands being a part of the narrative in web-series these days? 112 responses
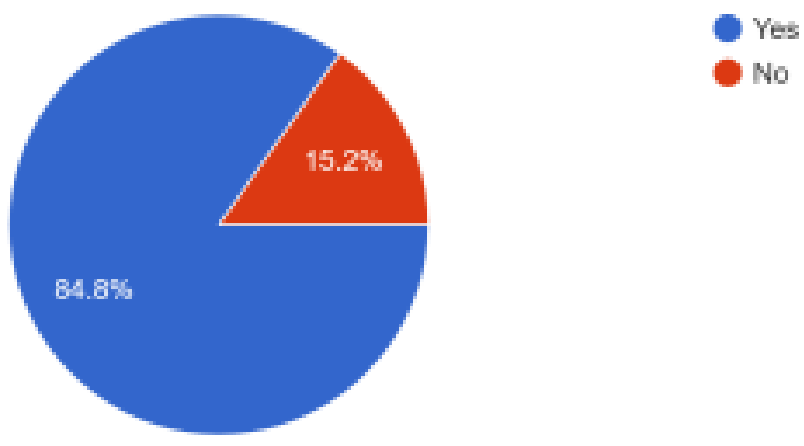

A large majority of $84.8 \%$ of respondents were noticing the integration of brands into web-series showing that the brand presence was memorable and being recalled to a large extent.15.2\% of the respondents however did not take note of the brand presence in their webseries viewing

experience. 


\section{Compared to brands embedded in web-series,you find traditional ads to be:} 112 responses

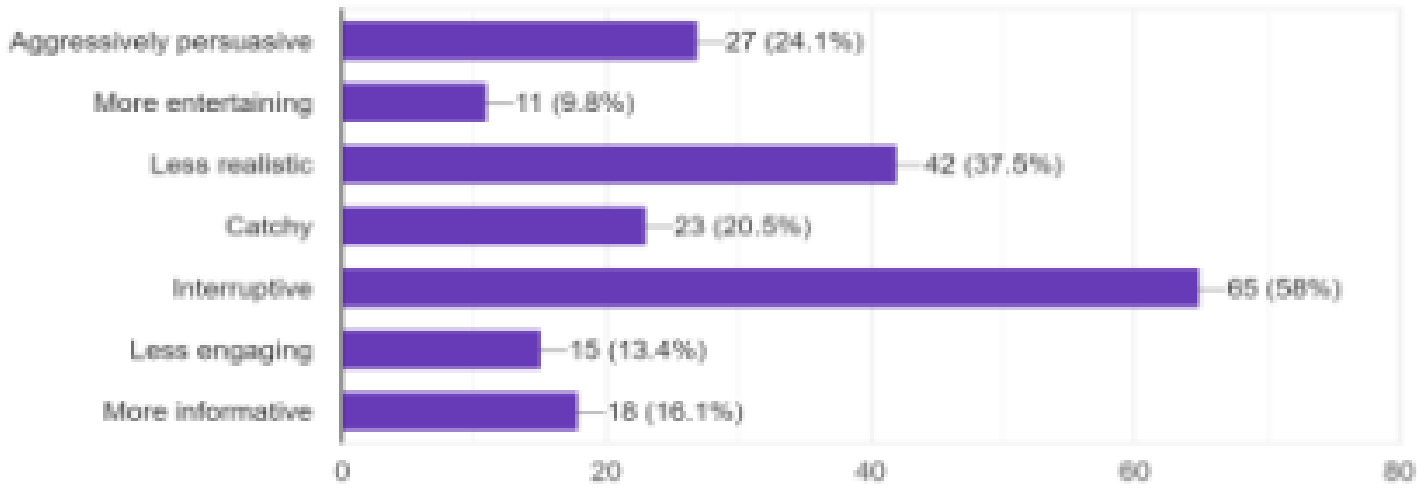

$58 \%, 37.5 \%, 24.1 \%$ and $13.4 \%$ of the respondents found traditional ads to be interruptive, less realistic, aggressively persuasive and less engaging respectively. While only $20.5 \%, 16.1 \%$, and $9.8 \%$ found traditional ads to be catchy, more informative and more entertaining respectively. This shows that suggests that traditional ads are viewed more negatively than positively amongst the respondents and thus aren't very effective at reaching Gen-Y and Gen-Z Indian consumers and hence necessitates exploring other promotional means to communicate the brand message to this section of consumers.

\section{You would be more likely to remember a brand through which of the following?}

112 responses

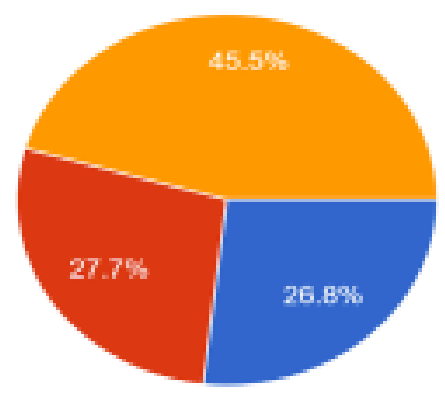

A commercial ad

A prominent placement/mention in a firm

The brand woven into the narrative of a web-series you like to watch

$45.5 \%$ of respondents said they would be more likely to remember a brand being part of a narrative of a web-series. $27.7 \%$ would remember an in-film placement better while only $26.8 \%$ said they would remember an ad better. This suggests that a brand being a part of the narrative of a series will result in higher brand memory. 


\title{
Has watching a web-series ever introduced you to a new brand?
}

\author{
112 responses
}
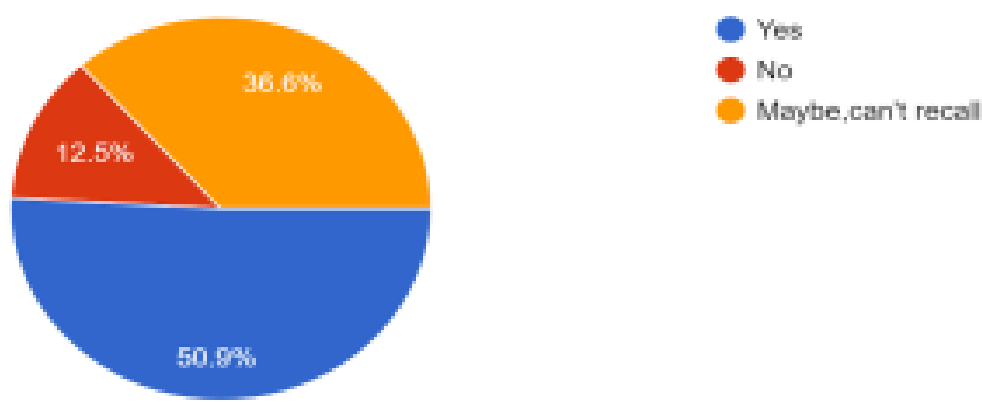

$50.9 \%$ of respondents said they were introduced to new brands through watching web-series. $36.6 \%$ of respondents couldn't recollect if they were introduced to a new brand suggesting that new brands have to effectively integrate themselves into the narrative to strongly position themselves in the consumers mind. The remaining $12.5 \%$ respondents weren't introduced to new brands through web-series.

\section{Which of the following do you recall better?}

\section{2 responses}

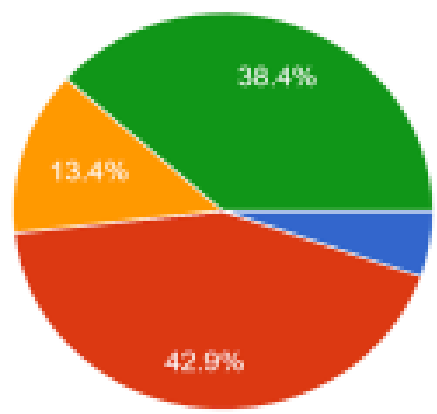

A TV ad of OLA

OLA in the web-series "Permanent Roommates"(TVF)

Neither

Havent watched "Permanent

Rocmmates*

$61.6 \%$ of respondents who had watched the series and $42.9 \%$ had recalled Ola in the series better than its TV ad. 5.3\% recalled the TV ad better while $13.4 \%$ couldn't recall either. "Permanent roommates" is the first and one of the most popular Indian web-series. The series had one central character who was an Ola cab driver. This enabled the repeated mention of Ola throughout the series hence reinforcing it in the viewer's mind through its relevance in the plot. 


\section{Which of the following brands do you recall from the web-series "Kota factory"(TVF)? \\ 112 responses}

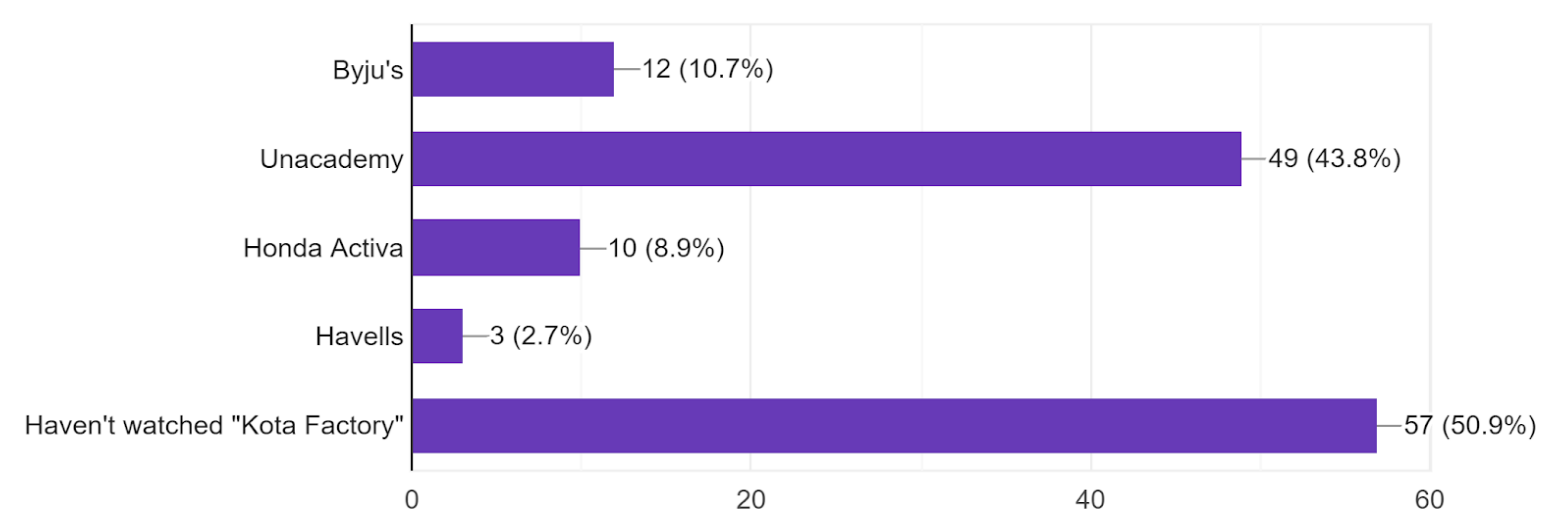

$66.1 \%$ of respondents had watched "Kota factory", $43.8 \%$ correctly recalled that Unacademy was the brand associated to the series. Only $10.7 \%$ said they recalled Byju's which is another learning app similar to Unacademy. This suggests that brands are able to differentiate themselves from competitors and position themselves successfully through web-series. $8.9 \%$ of respondents believed Honda-Activa was associated with the series even when it wasn't. This could be explained by the repeated use of scooters by the characters throughout the series. Only a mere $2.7 \%$ believed they recalled Havells that wasn't actually place anywhere in the series.

\section{Which of the following brands do you recall from the web-series "Little Things"(Dicemedia) S1?}

\section{2 responses}

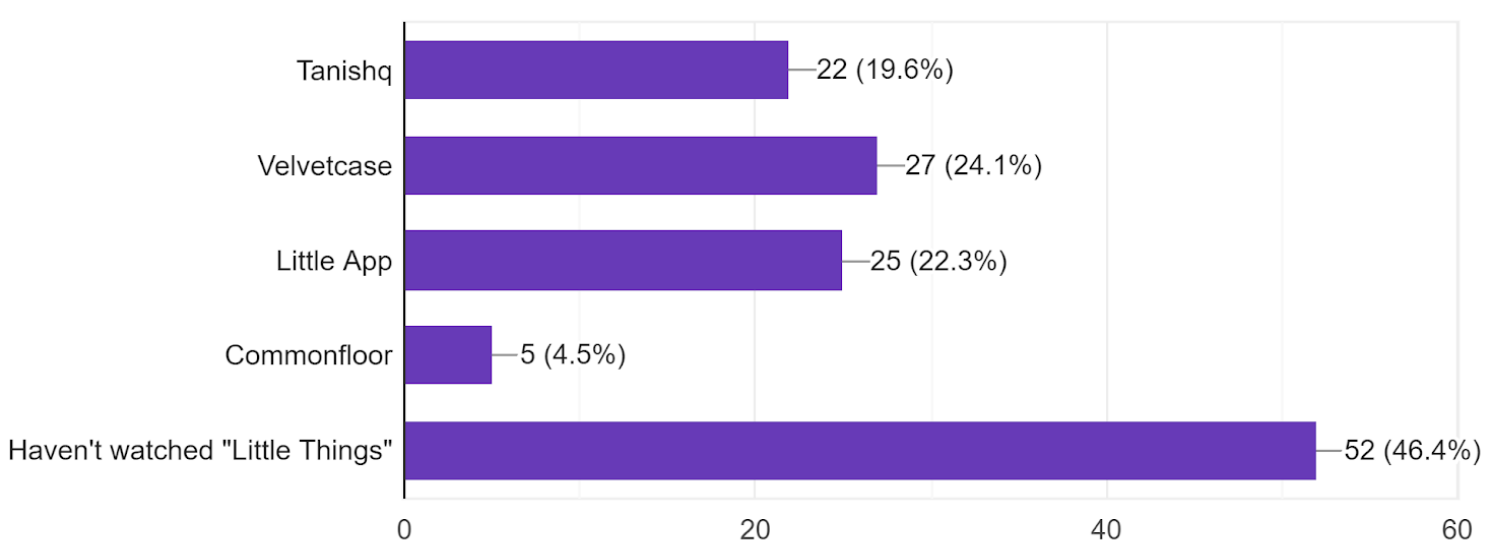

$53.6 \%$ of respondents had watched the series, $24.1 \%$ could correctly identify the brand placed which was velvet case( $24.1 \%)$ and little $\operatorname{app}(22.3 \%)$ which were more subtly placed and wasn't recurring within the narrative,however, a close $19.6 \%$ thought Tanishq was placed in the series which is another jewellery store like velvet case.This shows that brand differentiation might become difficult and hence impact can decrease if the brand isn't woven into the plot throughout and the audience isn't repetitively exposed to the brand. 


\title{
In the web-series "tripling" the siblings bond over a road-trip taken in Tata Tiago. Watching the series, did you associate the car to family-bonding?
}

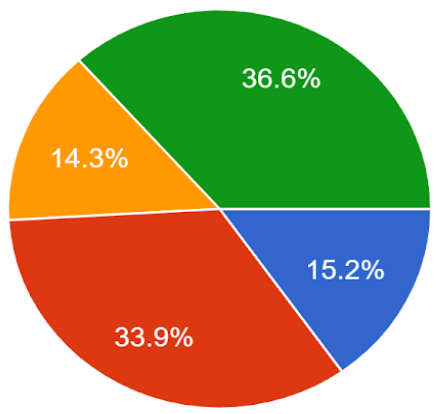

\author{
Yes \\ To some extend \\ No \\ Haven't watched "Tripling"
}

$62.8 \%$ of the respondents had watched "Tripling" $15.2 \%$ said that watching the series positioned the car to be associated to bonding and suitable for family-trips in their minds. $33.9 \%$ said that the brand was able to affect their perception of the brand to some extent. This shows that organic and skillful integration of the brand to the narrative results in effective communication of the brand message. $14.3 \%$ said their perception was unaffected.

\section{Does the use of a brand as a part of the every-day life of a character in a web-series affect your attitude towards the brand positively?}

112 responses

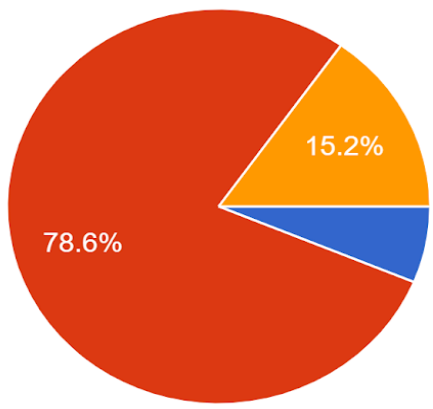

Always

Only if it relevant to the plot and seems natural

No, its annoying

$78.6 \%$ of respondents said that their attitude towards a brand can become positive if it is woven into the plot organically and holds relevance to it. $6.2 \%$ said that the brand attitude turned positive no matter what if it was seen to be used by the characters in the series as part of their everyday lives. While $15.2 \%$ found it to be annoying irrelevant of how the brand was integrated into the series. This suggests that branded web-series can be used to develop positive brand attitudes by tactfully incorporating it into the plot. 


\section{Does the likability of a brand increase when they create web-series that are engaging, resonate with your mindset ....ands on unconventional/taboo topics? 112 responses}
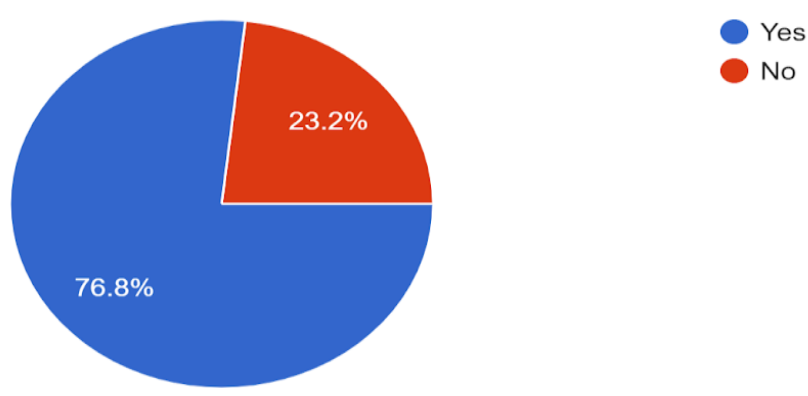

$76.8 \%$ of the respondents said that their likability towards a brand will increase if they produce web-series that resonate with their mindsets or discuss unconventional/taboo topics. This shows that producing web-series that revolve around issues that interest the target segments can be effective in building a positive brand image especially by demonstrating their stands on unconventional/taboo issues which would help the brand to connect with their target segments. $23.2 \%$ said it had no effect on their brand likability.

\section{How likely is it that you would prefer a brand associated to your favorite web-series over the alternatives available during a purchase? \\ 112 responses}

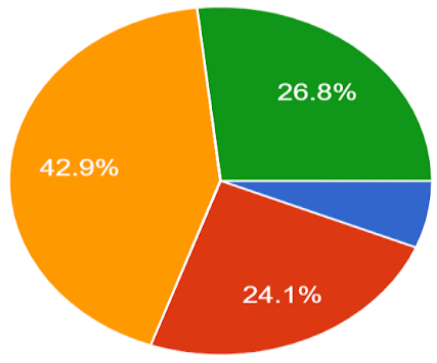

Would prefer it even if better alternatives are available.

Would prefer it even if the alternatives are equally good.

Would at least consider it now during purchases, if normally it wouldn't be considered.

Will not affect my preferences.

$6.2 \%$ of respondents said that they would prefer the brand associated with the series even if better alternatives are available. $24.1 \%$ said they would prefer it even if the alternatives are equally good. A majority of $42.9 \%$ said that they would now at least consider the brand during purchase even if they normally wouldn't. This shows us that even if branded web-series wouldn't lead to direct purchases, it would help develop a preference hence influences the comparison of alternatives and can enable brand switching. $26.8 \%$ said it wouldn't affect their preferences. 


\section{If a brand that you purchase/interact with is found to be associated with a popular web-series, would your choice be validated? \\ 112 responses}
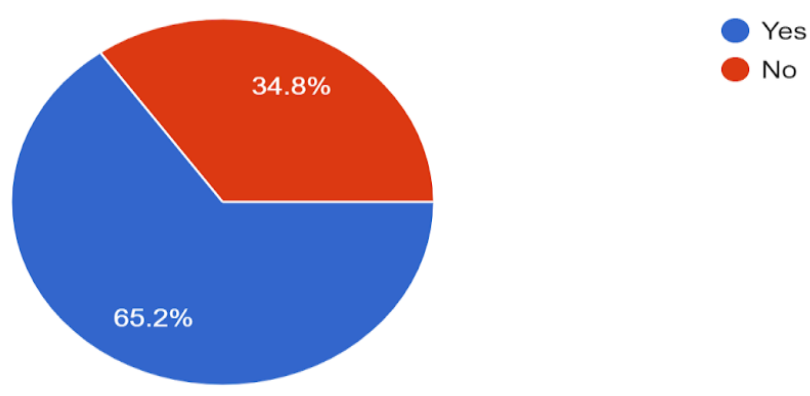

A majority of $65.5 \%$ of the respondents said that their purchase choice would be validated if the brand they purchased/interacted with was found to be associated with a popular web-series. This suggests that branded web-series can help build and increase brand loyalty. $34.8 \%$ said that their purchase choices wouldn't be validated due the association of the brand with a popular web-series.

\section{Do you think branding web-series is a more effective way for brands to reach young adults like you, than traditional advertising practices?}

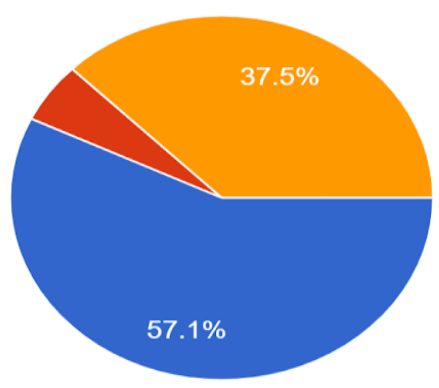

A majority of $57.1 \%$ of respondents believe that branded web-series are more effective at reaching and impacting Gen-Y and Gen-Z consumers like themselves. As observed earlier they hold a rather negative outlook towards traditional ads and it was also observed that branded web-series are well received by the majority of them. $37.5 \%$ were unsure if it was more effective while only $5.4 \%$ believe that traditional advertising practices are still more effective. The data suggest that branded web-series can be used by marketers to reach Gen-Y and Gen- $Z$ when the effectiveness of traditional advertising in reaching them is challenged.

\section{CONCLUSION}

The research carried out shows that the primary data collected to analyze the growing viewership of web-series and its use as an effective brand promotion tool in the Indian regional perspective is consistent with the secondary data which is primarily based in the western context. Availability of cheap data plans in India which enables easy access to the internet accompanied by a boom in the variety of content available online, a drastic shift is occurring amongst Indian Gen-Y and Gen-Z population from $\mathrm{TV}$ to online video streaming and several other over the top (OTT) platforms like Netflix, Amazon Prime, Hotstar and so on. The content on these platforms are largely fresh and provides a change for the viewers from the usual content on Indian TV and films hence is being welcomed with open arms especially by the younger Indian audience. As the popularity of traditional entertainment vehicles is declining among the younger population, advertising using them is becoming challenging for marketers. Producing or co-producing a web-series is an efficient use of advertising resources as it is found to create a lasting impact on the consumers and break through ad-clutter by increasing brand memory and recall since they affect both implicit and explicit memory due to repeated visual and audio exposure along with the storyline acting as a cue for memory retrieval. Branded web-series are most effective when the brand is woven into the storyline in a 
seamless manner where it fits in and thus increasing the credibility. This enables the brands to communicate the brand messages in a non-interruptive and engaging manner unlike traditional advertisements, hence lowering the consumer's tendency to avoid it or their defensiveness towards the persuasive message by the brand. Brands that create content that is relatable and discuss unconventional or taboo topics communicates the brand's values and stands and hence build a positive brand image and cultivate positive attitude of consumers towards the brand which would be beneficial in both short and long-run. Branded web-series impact the purchase decision process (information search and evaluation of alternatives stages) by creating brand awareness and developing brand preferences. However a direct relation between final purchase decision and a brand's association with a web-series cannot be established since it is influenced by several other factors. In a long-run, branded web-series increase brand loyalty by validating purchases through positive associations and building its reputation. Branded web-series can hence be employed by marketers as an alternative or in combination with other traditional advertising practices to stay ahead in the game and obtain maximum return on advertising resources during increasing brand competition and the changes occurring in advertising and digital landscape.

\section{DISCUSSIONS}

\section{Limitations}

The sample size is limited when compared to the large Indian population belonging to the selected age group. The scope of the research was limited and it doesn't include several lowertier cities which seems to be a major potential market for OTT platforms. The study was conducted prior to censorship mandates were put in place thus it doesn't take into account the impact the censorship would have on the type of content and hence the change it could bring about in the nature of brand collaborations and how the effectiveness of these branded web series can be altered.Absolute honesty was requested from respondents but not guaranteed.

\section{Future Research}

Cultural and individual differences can be accounted for when comparing the impact on consumers because these factors could influence perceptions of these branded web-series. The degree to which other elements of the web series such as the cast, their popularity and the audience's identification with them influence the effectiveness of brand collaborations can be studied. The potential of regional branded content can be explored to target specific markets more effectively.

\section{ACKNOWLEDGEMENT}

First and foremost, I want to express my sincere gratitude to my guide Dr.Chaitanya Vyas..The director and the dean of the School of Liberal Studies, Dr. Nigam Dave and Dr. Ritu Sharma, for providing me with various opportunities throughout the entire program to explore and learn.I would also like to express my heartfelt gratitude to the department of marketing, and the marketing faculty who encouraged and nurtured my interest in marketing and guided me through its depths, providing constant s

\section{REFERENCES}

[1] 1.Kakkar, Kalyani Nayak, A. (2019). Analysis of Product Placement in Web Series and Its Influence on Consumer Buying Behavior. Global Journal Of Management And Business Research

[2] 2.Balasubramanian, Siva \& Karrh, James \& Patwardhan, Hemant. (2006). Audience Response to Product Placements: An Integrative Framework and Future Research Agenda. Journal of Advertising. 35. 115-141. DOI: 10.2753/JOA0091-3367350308.

[3] 3.Fulgoni Gian \& Pettit, Raymond \& Lipsman Andrew. (2017). Measuring the Effectiveness of Branded Content across Television and Digital Platforms: How to Align with Traditional Marketing Metrics While Capturing What Makes Branded Content Unique. Journal of Advertising Research. 57. 362-367. DOI:10.2501/JAR-2017-046.

[4] 4.Hudson Simon \& Hudson David. (2006). Branded Entertainment: A New Advertising Technique or Product Placement in Disguise? Journal of Marketing Management. 22. 489-504. DOI:10.1362/026725706777978703.

[5] 5.Karrh, James A. \& Mckee, Kathy Brittain \& Pardun, Carol J., (2003)"Practitioners' Evolving Views on Product Placement Effectiveness," Journal of Advertising Research, Cambridge University Press, vol. 43(2), pages 138-149.

[6] 6.Komal Nagar(2016) "Consumer Response to Brand Placement in Movies Investigating the Brand-Event Fit”VIKALPA The Journal for Decision Makers 41(2) 149-167 https://doi.org/10.1177/0256090916642678

[7] 7.Marian Friestad, Peter Wright(1994), The Persuasion Knowledge Model: How People Cope with Persuasion Attempts, Journal of consumer research, Volume 21, Issue 1, Pages 1-31

[8] 8.Min-Wook Choi(2015). A Study on the Branded Content as Marketing Communication Media in the Viewpoint of Relational Perspective. Indian Journal of Science and Technology, Vol 8(S5), 116-123,

[9] 9. Pola B. Gupta Ph.D. \& Stephen J. Gould Ph.D. (1997) Consumers Perceptions of the Ethics and Acceptability of Product Placements in Movies: Product Category and Individual Differences, Journal of Current Issues \& Research in Advertising, 19:1, 37-50, DOI: 10.1080/10641734.1997.10505056

[10] 10.Pola B. Gupta \& Kennth R.Lord (1998) Product Placement in Movies: The Effect of Prominence and Mode on Audience Recall. Journal of Current Issues \& Research in Advertising,20:1,47-59, DOI: 10.1080/10641734.1998.10505076.

[11] 11..Russell, C. A. (2007). Advertainment: Fusing Advertising and Entertainment. Ann Arbor, Mich.: University of Michigan Yaffe Center for Persuasive Communication.

[12] 12.Teixeira, Thales S.(2014) "The Rising Cost of Consumer Attention: Why You Should Care, and What You Can Do about It." Harvard Business School Working Paper, No. 14-055,

[13] 13..S.B Diwan(2017) "Consumer attitudes towards product placements in movies and TV serials"IJCRT,Volume 5,Issue 4,ISSN:2320-2882

\section{WEBLIOGRAPHY}

[1] Adage, 2008: Marketers losing confidence in TV

[2] https://adage.com/article/media/marketers-losing-confidence-tv/125233

[3] Covid-19 pushes up OTT subscription growth by $60 \%$ : BCG report

[4] https://www.business-standard.com/article/companies/covid-19-pushes-upott-subscription-growth by-60-bcg-report-120121601311_1.html

[5] Businesstoday, 2019: Hotstar beats Netflix, Amazon Prime Video to become top OTT platform in India

[6] https://www.businesstoday.in/current/corporate/hotstar-beats-netflixamazon-prime-video-to-beco me-top ott-platform-inindia/story/375812.html

[7] Datareportal, 2019: Digital 2019 India.

[8] https://www.slideshare.net/DataReportal/digital-2019-india-january-2019v01

[9] Financialexpress, 2019: How advertisers are leveraging the movie screen

[10] https://www.financialexpress.com/industry/how-advertisers-leveragingmoney-on-the-movie-screen/ 1602651/ 
[11] Hindustantimes, 2016: Indian audiences welcome web series with open arms https://www.hindustantimes.com/tv/web-series-the-next-big-thing-on-theinternet/story-ZvJqoSdi3 ZqtszsZrGMRKL.html

[12] Livemint, 2018: Video streaming market in India to reach $\$ 5$ billion by 2023 : BCG report https://www.livemint.com/Consumer/P9ZSN91tXV9eWM3mXRndrJ/Vide o-streaming-market-in-I ndia-to-reach-5-billion-by-2023.html Livemint, 2016: Friends most watched English show on Indian TV in January-June https://www.livemint.com/Consumer/dDVVsqf2rxjIcyo7u24g8I/WhatIndia-watched-in-English-ent ertainment-between-January.html

[13] Lockdown-led push for OTT platforms set to carry on into 2021

[14] https://www.livemint.com/industry/media/lockdown-led-push-for-ottplatforms-set-to-carry-on-into -2021-11608102539208.html Socialsamosa, 2017: Original Content and KPIs - Are big budget web series paying off? https://www.socialsamosa.com/2017/12/indian-original-web-series/
[15] Statista, 2019: Digital population in India as of January 2019 (in millions)

[16] https://www.statista.com/statistics/309866/india-digital-population/

[17] India Smart TV And OTT Market - Growth, Trends, COVID-19 Impact, And Forecasts (2021 - 2026)2021 https://www.mordorintelligence.com/industryreports/india-smart-tv-and-ott-market

[18] FICCI Frames 2020: How OTT transformed into a mainstream media platform from a niche platform https://ficci.in/ficci-in-newspage. asp?nid $=23755$

\section{AUTHORS}

First Author - Greeshma Bharathan,BBA(hons),Pandit Deendayal Energy University,greeshmabharat@gmail.com 